\title{
Improving the Performance of Antenna using Substrate Integrated Waveguide Coupler
}

\author{
S. Rajkumar', S. V. Saravanan', S. Devendran² and M. Krishna Kumar ${ }^{2}$ \\ 'Department of EEE, AMET University, Plot No.135, East Coast Road, Kanathur, Chennai - 603112, Tamil Nadu, \\ India; srajece@gmail.com, svsaravanan@gmail.com \\ ${ }^{2}$ Department of ECE, Chandy College of Engineering, Chandy Nagar, Mullakadu, Tuticorin-628 005, Tamil Nadu, \\ India; devendran1.2007@gmail.com, krishna18innet@gmail.com
}

\begin{abstract}
A compact antenna with a coupler is laid down using Substrate Integrated Waveguide (SIW) technique, which operate at X-band of frequencies. The SIW coupler has a SIW section which includes inserted metallic post. These metallic post acts as an inductive-post. SIW innovation is the most talented contender for the achievement of millimetre wave (mm-wave) coordinated circuits. Supported on planar dielectric substrate with bottom and top metal layers implanted with coated metal holes, it offers a compact, low cost, less loss and flexibility. The SIW has dynamic as well as passive components emanating area on the similar substrate. SIW technology has some attractive advantages, such as compact size, low loss, easy construction, low weight, high integration and is suited for all microwave and millimetre-wave works. The utilization of SIW technology encourages us to trim down return loss when weighed against other printed advances. The manufacturing process can simply be finished by means of normal Printed Circuit Board (PCB) process, where this present procedure's cost will be shortened when assessed with conventional waveguides. The SIW coupler more frequently utilized as a part of radar, point-to-point radio and satellite. Simulations results come about demonstrate the coupler's execution having low insertion loss, low return loss, and expansive operational data transmission and enclose fine seclusion.
\end{abstract}

Keywords: Micro-Strip Line Feed, Micro-Strip Patch Antenna, Printed Circuit Board, Substrate Integrated Waveguide Coupler

\section{Introduction}

Wireless systems are giving more interest in recent trend, which is used for each and every microwave and millimeter-wave functions. The assortments of uses have been proposed in the range of $60-94 \mathrm{GHz}$ frequencies, including sensors, radars, remote systems and satellite. The active part is the core of the system, which has mixers, local oscillator and low noise amplifiers along with others. The above apparatus are included on chip-sets format in low cost.

System in Package ( $\mathrm{SiP}$ ) conquer the boundaries of the chip-setsf, large numeral of chip-sets are joint in a single package which is included along with other components. These components are made-up of diverse technologies. The planar technology is commonly used under low frequencies.
A SIW technology is the utmost hopeful procedure ${ }^{2-4}$ The SIWs are fused like waveguides in the midst of two sided metalized gaps, which is set in with the substrate integrated waveguide (Figure 1). Likewise, the non planar rectangular waveguide be able to made into planar waveguide. The above can be processed using regular PCB or Low Temperature Co-fired Ceramic technology (LTCC).

Furthermore, SIW set-ups hold back utmost benefits of conventional metallic waveguides, that is to say high quality factor and high power taking care of potential with self-dependable electrical protection. The most vital advantage of SIW innovation is its probability to assemble every one of the segments on a similar substrate, including active and passive elements and also antennas. Also, there is the likelihood to accumulate more chip sets on the similar substrate. By means of this technique, there

${ }^{*}$ Author for correspondence 
is no need for supplementary technologies to move the signals from one device to other, so this in turn reduces the losses. This is the best means to expand the idea of system in package to the System-on-Substrate $(\mathrm{SoS})$,

\section{Coupler and Antenna Design}

The Coupler and antenna are realized on a Rogers RT5880 substrate that has 2.2 comparative dielectric constant and $0.8 \mathrm{~mm}$ width. The substrate mass is $10.77 \mathrm{~mm}(\mathrm{~L}) \mathrm{x}$ $13.17 \mathrm{~mm}(\mathrm{~W})$. The resonant frequency is selected in the $\mathrm{X}$-band range.

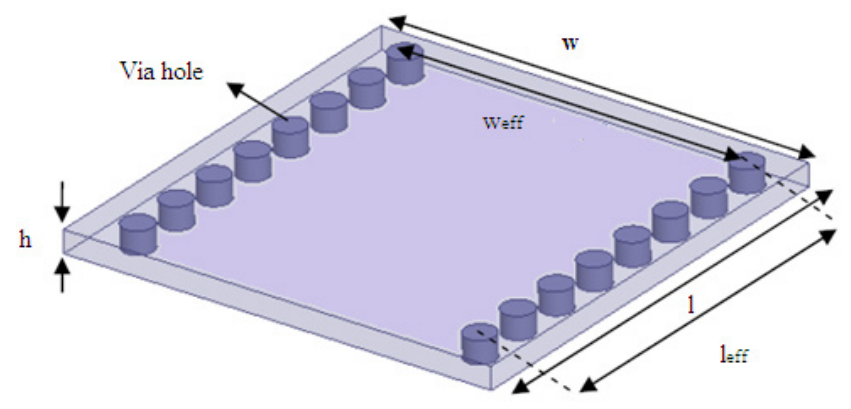

Figure 1. Fundamental arrangement of SIW.

The phase shifters combine the SIW concept and the post based technique, similarly the projected construction is revealed in Figure 2. In the SIW line, the vertical wall of a rectangular waveguide is replace by a sequence of metal posts, the metal posts are made by drilling holes in the substrate. The SIW coupler is made by piercing holes on the apex and foot of the substrate and the manufactured waveguide shall be employed to change the phase of the event wave by varying their location in the substrate and its diameter?

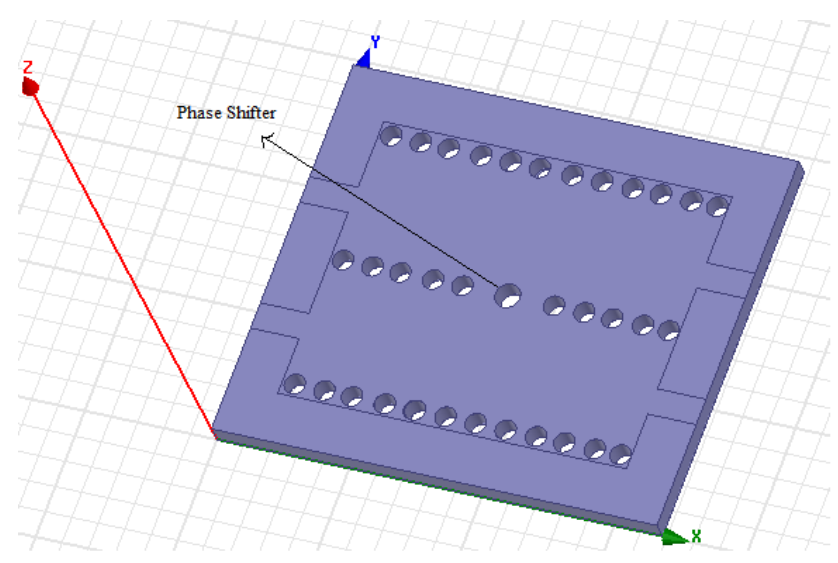

Figure 2. Design of SIW Coupler.
The planned SIW phase shifter was designed by applying the rules given below

$$
\begin{aligned}
& d<\frac{\lambda_{g}}{5} \\
& p \leq 2 d
\end{aligned}
$$

The E-shaped micro-strip patch antenna has a substrate dielectric constant $\left(\varepsilon_{\mathrm{r}}\right)$ is 2.2 and substrate width is $\mathrm{h}=0.8 \mathrm{~mm}$. The width and length of the micro-strip antenna are decided using the below given formula

$w=c_{0} / 2 f_{r} \sqrt{\left(\frac{2}{\varepsilon_{r}+1}\right)}$

where, $c_{0-}$ velocity of light in free space

$\varepsilon_{r e f f}=\left(\varepsilon_{r}+1\right) / 2+\left(\varepsilon_{r}-1\right) / 2\left[1+\mathcal{L}\left(\frac{h}{w}\right)\right]^{-\frac{1}{2}}$

$w / h>1$

where, $\varepsilon_{\text {reff }}$ is the effective dielectric constant and the width-to-height ratio $(\mathrm{W} / \mathrm{h}), \Delta l$ is the dimension of patch along with its length and the normalized additional length, is

$$
\frac{\Delta l}{h}=0.412 \frac{\left(\varepsilon_{\text {reff }}+0.3\right)}{\left(\varepsilon_{\text {reff }}-0.258\right)} \frac{\left(\frac{w}{h}+0.264\right)}{\left(\frac{w}{h}+0.8\right)}
$$

The length of patch can be found using $l=c_{0} / 2 f_{r} \sqrt{\varepsilon_{r e f f}}-2 \Delta l$

In this manuscript, the E-shaped micro strip patch antenna designed with desired width $(\mathrm{W})(13.17 \mathrm{~mm})$ and length $(\mathrm{L})(10.77 \mathrm{~mm})$. The width of dielectric layer is 0.79 $\mathrm{mm}$. In this section we will discuss about the parameters effect depends on the act of designed E-shaped micro strip antenna. When the return loss is minimum the antenna was set in feeding point. By altering the position of feeding point this will change the various terms which are related with antenna. Figure 3. gives a HFSS top view of $\mathrm{E}$ shaped antenna with above mentioned dimensions?

The SIW was produced using apex and foot metal substrate planes and has two arrays with passing through holes in the both side walls as shown in Figure 1. Fleeting through hole must short to both the planes in order to regulate perpendicular present paths; if not 
the transmission characteristics of SIW will consider tainted. Since the perpendicular metal wall is restored by pass through holes, the signals propagate through the waveguide with tiny losses.

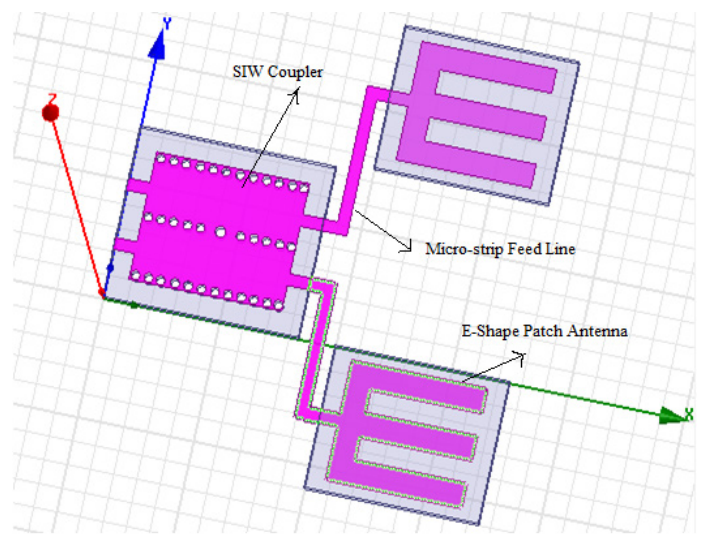

Figure 3. Micro strip Patch Antenna Using HFSS.

By means of equivalence resonant frequency, the SIW void size is determined from

$$
f_{101}=\frac{c}{2 \pi \sqrt{\mu_{r} \varepsilon_{r}}} \sqrt{\left(\frac{\pi}{w_{\text {eff }}}\right)+\left(\frac{\pi}{l_{\text {eff }}}\right)}
$$

This is to verify that the SIW coupler will convey $T E_{10}$ mode in working frequency range. In SIW the $E$-field distribution is similar to conventional rectangular waveguide. The SIW effective length and width void can determine from:

$$
\begin{aligned}
& w_{\text {eff }}=w-\frac{d^{2}}{0.9 p} \\
& l_{e f f}=l-\frac{d^{2}}{0.9 p}
\end{aligned}
$$

Where, $l$ and $w$ are the extent of the SIW cavity and thickness. However $d$ is diameter of the cylindrical hole, $p$ is pitch (distance between center to center of adjacent pass hole).

Micro-strip line supply is one of the simple techniques to manufacture, as it is just a conducting strip connection through the patch and it consider as the patch extension. The micro-strip line feed is a simple feed method and easy to match and model which control the inset location.

\section{Simulation Results}

\section{A. Return Loss}

Figure 4. demonstrates the simulated and calculated reflection coefficients for the summation and differentiation ports. $S_{11}$ and $S_{22}$ are the sum and difference ports reflection coefficients, respectively. Antenna has broadband impedance matching character for the 8-12$\mathrm{GHz}$ frequency band. Since the calculated reflection coefficients are below $-10 \mathrm{~dB}$ shown in Figure 5.

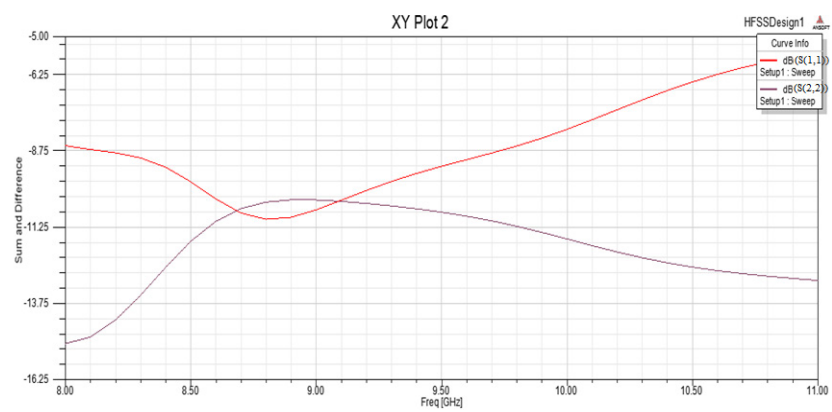

Figure 4. Addition and Differentiation reflection coefficients.

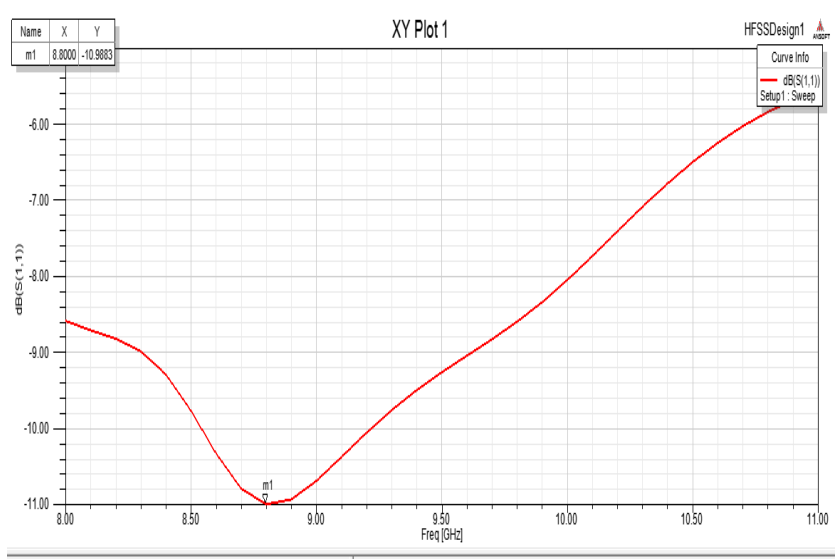

Figure 5. Simulated Return loss graph.

\section{B. Radiation Pattern}

The structures achieve good quality radiation at broadside. Antenna gain is roughly around $6 \mathrm{dBi}$. The power height of the radiation pattern is equal for both positive and negative side shown in Figure 6.
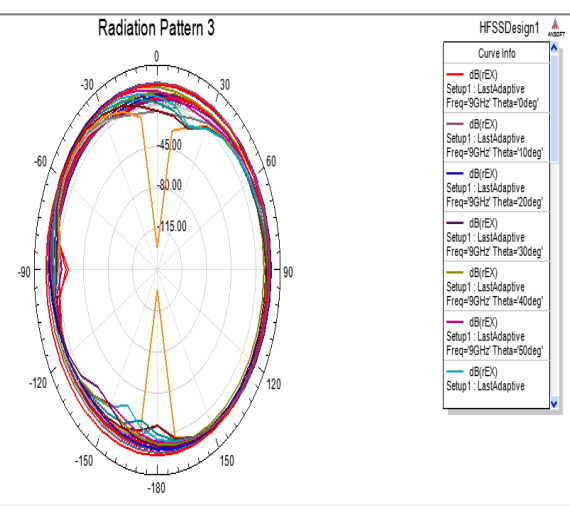

Figure 6. Radiation pattern in polar plot. 
The radiation pattern is given in $3 \mathrm{D}$ as shown in Figure 7. The polar plot represents the directivity of antenna at frequency in $6 \mathrm{dBi}$. This radiation pattern also shows that by changing feed point, we can get the radiation in the circular polarization.

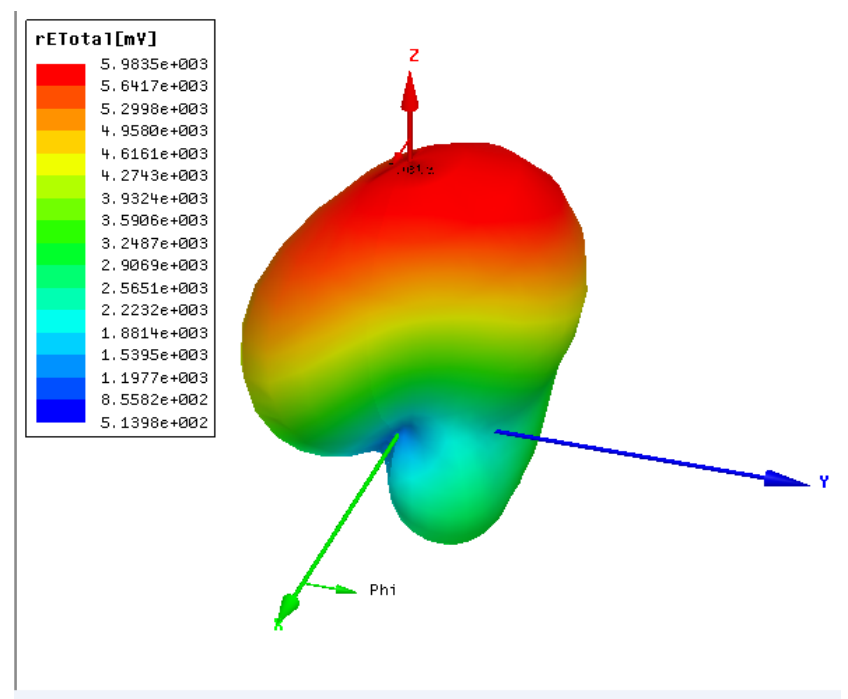

Figure 7. Radiation pattern in 3D.

\section{Conclusion}

From the simulation analysis of the antenna it is observed that the designed E-shaped micro-strip antenna has a gain of $4.7 \mathrm{~dB}$ and directivity of the antenna is $6 \mathrm{dBi}$. This kind of coupler is appropriate for high mass integrated microwave and millimeter wave applications. The design method was discussed and the return loss was minimized and the performance of patch antenna has been amplified. By using SIW techniques, the compact sized couplers can be produced and they are easier to integrate with other planar circuits at ease.

\section{References}

1. Gaynor MP. System in package RF design and applications. Artech House. 2007.

2. Deslandes $\mathrm{D}, \mathrm{Wu} \mathrm{K}$. Single-substrate integration technique of planar circuits and waveguide filters. IEEE Trans. Microw Theory Tech. 2003; 51(2):593-96.

3. $\mathrm{Xu} \mathrm{F}, \mathrm{Wu} \mathrm{K}$. Guided-wave and leakage characteristics of substrate integrated waveguide. IEEE Trans. Microw Theory Tech. 2005; 53(1):66-73.

4. Deslandes D, Wu K. Accurate modeling, wave mechanisms and design considerations of a substrate integrated waveguide. Ieee Trans. Microw Theory Tech. 2006; 54(6):251626.

5. $\mathrm{Wu} \mathrm{K}$. Towards system on substrate approach for future millimeterwave and photonic wireless applications. Proc Asia Pacific Microwave Conf. 2006.

6. Denidni TA, Lebel J, Sellal K and Talbi L. Design and implementaion of a substrate integrated waveguide phase shifter. IET Microw Antennas Propag. 2008; 2(2):194-99.

7. Ajay Yadav, Bhadrasheela Chauhan, Aanchal Jain. Micro-strip Symmetrical E-Shape Patch Antenna for the Wireless Communication Systems. ISO 9001:2008 Certified Journal. 2012; 2(12). ISSN 2250-2459.

8. Indrasen Singh and Tripathi VS. Micro strip Patch Antenna and its Applications: a Survey. Int. J. Comp. Tech. Appl. 2011; 2(5):1595-99.

9. Hemendra Kumar, Ruchira Jadhav, Sulabha Ranade. A Review on Substrate Integrated Waveguide and its Micro-strip Interconnect. 2012; 3(5):36-40. ISSN: 2278-2834, ISBN: 2278-8735.

10. Layne A Berge. Comparison on the Coupling between Substrate Integrated Waveguide and Micro-strip Transmission Lines for Antenna Arrays. 2013 7th European Conference on Antennas and Propagation (EuCAP). 